\title{
Development and validation of a food-frequency questionnaire for the determination of detailed fatty acid intakes
}

\author{
Marie M Cantwell ${ }^{1,2} \uparrow$, Michael J Gibney ${ }^{2}$, Denis Cronin ${ }^{3}$, Kate M Younger ${ }^{1}$, \\ John P O'Neill ${ }^{3}$, Linda Hogan ${ }^{1}$ and Mary AT Flynn ${ }^{1,4, *}$ \\ ${ }^{1}$ Department of Biological Sciences, Dublin Institute of Technology, Republic of Ireland: ${ }^{2}$ Department of Clinical \\ Medicine, Trinity Centre for Health Sciences, University of Dublin, Trinity College, Republic of Ireland: ${ }^{3}$ University \\ College Dublin, Republic of Ireland: ${ }^{4}$ Nutrition and Active Living, Health Promotion and Disease Prevention, \\ Calgary Health Region, PO Box 4016, Station C, 5th Floor, Centre 15, 1509 Centre Street SW, Calgary, Alberta, \\ Canada T2T 5T1
}

Submitted 9 September 2003: Accepted 12 August 2004

\begin{abstract}
Objective: To validate a fat intake questionnaire (FIQ) developed to assess habitual dietary intake while focusing on the assessment of detailed fatty acid intake including total trans unsaturated fatty acids (TUFA).

Design: An 88 food item/food group FIQ was developed using a meal pattern technique. Validation was achieved by comparison with dietary intake assessed by a modified diet history (DH) in a cross-over design. Eighty-four individuals supplied adipose tissue biopsies for linoleic acid and total TUFA analysis as an independent validation of the FIQ and DH.

Setting: Medical Centre, Dublin Airport, Republic of Ireland.

Subjects: One hundred and five healthy volunteers ( 43 females and 62 males aged 23-63 years).

Results: Significant correlations $(P<0.0005)$ were achieved for intakes of energy (0.78), total fat (0.77), saturated fat $(0.77)$, monounsaturated fat $(0.63)$, polyunsaturated fat (0.73), TUFA (0.67) and linoleic acid (0.71) assessed by the FIQ compared with the DH. Linoleic acid intake assessed by the FIQ and the DH was significantly correlated with adipose tissue concentrations $(r=0.58$ and 0.49 , respectively; $P<0.005)$; however, total TUFA intake was poorly correlated with adipose tissue concentrations ( $r=0.17$ and 0.10 for FIQ and DH, respectively).

Conclusions: The FIQ compared favourably with the DH in assessing habitual diet, in particular fatty acid intake. In addition, the FIQ was successfully validated against the linoleic acid composition of adipose tissue, an independent biomarker of relative fatty acid status. The FIQ could therefore be used as an alternative to the DH as it is a shorter, less labour-intensive method.
\end{abstract}

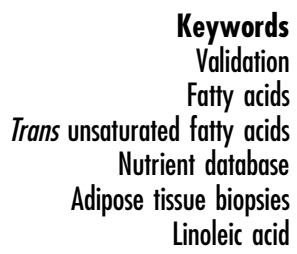

Keywords

Validation Fatty acids

Nutrient database

Linoleic acid
Epidemiological and laboratory research suggests that diets high in fat are associated with an increased risk of developing cardiovascular disease, some cancers and possibly obesity ${ }^{1}$. Studies suggest that individual fatty acids within the same class differ in their effects on blood lipids and affect cardiovascular disease risk differently ${ }^{2}$. Hu et $a l^{3}$ examined dietary intake of saturated fatty acids (SFA) and coronary heart disease (CHD), and showed that while short- to medium-chain (4:0-10:0) SFA were not significantly associated with an increased risk of $\mathrm{CHD}$, longer-chain SFA (12:0-18:0) were each separately

†Current address: Cancer Prevention Fellowship Program, Division of Cancer Prevention, National Cancer Institute, National Institutes of Health, USA. associated with a small increase in risk. Cis monounsaturated fatty acids (MUFA), e.g. oleic acid, have a lowering effect on low-density lipoprotein (LDL)-cholesterol and a neutral effect on high-density lipoprotein (HDL)-cholesterol levels, whereas trans MUFA, e.g. elaidic acid, raise LDL-cholesterol while lowering HDL-cholesterol levels ${ }^{4}$. The assessment of individual fatty acid intake is however highly complex and limited to the nutrient database used to analyse dietary data.

Dietary assessment of fatty acid intake is particularly challenging as the fatty acid composition of certain foods (e.g. margarine, cooking fat and biscuits) differs dramatically between brands. In addition, manufacturers of margarine and cooking fat may change the component oils used depending on production costs. For example, 
the species and content of fish oils used may change depending on availability and cost, thereby changing the fatty acid composition of the margarine or fat produced and finally the products manufactured using this fat. Therefore, dietary data should ideally be analysed using food composition data that have been collected during the same reference period.

The 7-day diet history (DH) method, standardised for use in the Irish National Nutrition Survey ${ }^{5}$, has previously been validated for energy intake against the doubly labelled water method in adolescents ${ }^{6}$. The DH assesses habitual dietary intake and can be modified to assess brands of processed foods eaten and therefore fatty acid intake; however, this increases the administration time required. Food-frequency questionnaires (FFQs) are therefore frequently used, as they are less labourintensive. The relative validity of a newly developed FFQ must in general be assessed by comparison with a reference method (a previously validated dietary assessment method, e.g. DH). However, Hirsch et al. ${ }^{7}$ suggested the use of a biological index of intake as an independent validity check. It has been demonstrated for example that the fatty acid composition of subcutaneous adipose tissue reflects dietary fatty acid intake over the previous 2 years and can therefore be used as a biological index of fatty acid intake. A biomarker serves as an independent measure of intake unbiased by self-reporting or changes in the fatty acid composition of the food supply from season to season.

The specific objectives of the present paper are:

1. to describe the development of a food/nutrient database which includes the fatty acid and total trans unsaturated fatty acids (TUFA) content of 225 foods analysed specifically for this study;

2. to describe the development and validation of a fat intake questionnaire (FIQ) developed to assess habitual dietary intake, with particular emphasis on fatty acid intake, by comparison with the DH method; and

3. to describe the validation of the FIQ by comparison with the fatty acid composition of adipose tissue as an independent marker of relative fatty acid status.

\section{Methods}

\section{FIQ development}

An FIQ was developed using food intake data assessed in a previous study of 153 healthy Irish adults ${ }^{8}$. This included the development of a comprehensive list of foods that accounted for the total fat intake and 95\% of total energy intake of individuals in this study. Food items with a similar nutrient content and of similar portion size were grouped together; for example all types of root vegetable were assessed as one food group. The FIQ was designed to record additional information on method of cooking, sauces added, the type and amount of fat used both in cooking and at the table, and the consumption of fat on meats.

The FIQ, which was pilot-tested in a group of 20 healthy adults (10 males, 10 females), was modified slightly for clarity. The final questionnaire included 88 food items or food groups and was structured to follow a typical daily meal pattern; i.e. all foods usually consumed at breakfast were assessed first, followed by foods typically eaten at other meals. For example, bread intake was assessed for four eating occasions: breakfast, lunch, dinner and snacks. For certain foods e.g. biscuits, the frequency of consumption of all types of biscuits was recorded and additional questions collected information regarding the amount, type and brand chosen. Intakes of mixed dishes, cakes, confectionery and take-away foods were also assessed in this way. The reference period included the four weeks preceding the interview. The frequency of consumption of each food item was recorded as frequency per day, per week, per fortnight or per month.

Standard portion sizes were derived from commonly used household units for each food listed (e.g. pre-sliced bread, pat of butter, teaspoon, tablespoon, cup, etc.). The FIQ recorded the subject's regular portion size of each food eaten relative to this standard portion size (e.g. 4 slices of bread, $1 / 2$ teaspoon of sugar, etc.). For a limited number of foods (namely breakfast cereals, meat, fish and mixed dishes) a semi-quantitative approach was necessary and portion sizes were described as small, medium and large? . To identify brands of food consumed, an atlas of 142 photographs of different brands of biscuits, cakes, pastries, breads, cooking fats, dairy and non-dairy spreads was developed specifically for this study. Finally, the FIQ was developed for administration by a trained nutritionist as a quick method of measuring fat intake.

\section{Compilation of a food/nutrient database}

Two hundred and twenty-five foods (cakes, biscuits, pastries, breads, dairy and non-dairy spreads, cooking fats, hard margarines, fruit-filled pies and snack foods) were analysed for their individual fatty acid and total TUFA content $^{10,11}$. Fatty acid methyl esters (FAMEs) were separated by gas chromatography and identified by comparison with standard samples of known methyl esters. Fatty acids with 20-22 carbon atoms were calculated as one group, making no distinction between SFA, MUFA or PUFA, or whether the configuration of the double bonds was cis or trans. The presence of $\mathrm{C}_{20}$ and $\mathrm{C}_{22}$ fatty acids indicated the use of marine oils in the production of a food. The total TUFA content was analysed using infra-red spectroscopy ${ }^{10,11}$. The analysis of foods was carried out according to the methods outlined by $\mathrm{O}^{\prime} \mathrm{Neill}^{10}$ and Cronin and O'Neill ${ }^{11}$. As a result of this analysis, the following fatty acid profile was established for each food: 12:0, 14:0, 16:0, 18:0, 16:1, 18:1, 18:2, 18:3, $\mathrm{C}_{20}+\mathrm{C}_{22}$ and total TUFA content. 
UK food composition tables (FOODBASE) were modified as follows to incorporate the fatty acid data of the 225 Irish foods analysed. The nutrient record of a similar food in the UK database was copied and the fatty acid profile was substituted, producing a new food record that included the carbohydrate, protein and micronutrient content of the UK food and the fatty acid composition of the Irish food. New food records were therefore developed for each of the 225 foods analysed. Checks for internal consistency of the database included comparison of calculated measurements with expected values for each database entry as described by Buzzard et al. ${ }^{12}$.

\section{Validation study}

Of 2000 employees invited through a mailing system and advertisement in a company magazine, 317 volunteered for the study. One hundred and fifty-two individuals were excluded as a result of the following criteria: taking prescription medication, lipid abnormalities or aged $<20$ or $>65$ years. Of the 165 suitable healthy volunteers who were recruited, 54 were missing dietary intake data and six reported an implausible dietary intake. Subject information for the remaining 105 volunteers is shown in Table 1. Ethical approval was received from the ethics committee of the Federated Dublin Voluntary Hospitals and all participants provided informed written consent.

The dietary intake of all participants was assessed twice, once with the FIQ and once with the modified DH method (reference method). The $\mathrm{DH}$ method described by Livingstone et $\mathrm{al}^{6}{ }^{6}$ was modified to assess individual fatty acid intake by assessing the brands of foods chosen with the photographic atlas described previously. The study was conducted using a cross-over design whereby equal numbers of participants were assessed using the FIQ and DH history first. A four-week interval between dietary assessments prevented information carryover from the first to the second assessment. Anthropometric measurements were recorded at both interviews. Body weight, without shoes and jacket, was assessed on a SECA scale to the nearest $0.1 \mathrm{~kg}$. Height was recorded in $\mathrm{cm}$.

\section{Laboratory analysis}

Subcutaneous adipose tissue samples were aspirated from the abdomen using a modification of the method described by Hirsch et $a l^{7}$, and biopsies that were adequate for analysis were obtained from 84 of the volunteers. Accurately weighed samples of approximately $10 \mathrm{mg}$ adipose fat were dissolved in $0.1 \mathrm{ml}$ isopropyl ether and transesterified at ambient temperature with $0.1 \mathrm{ml}$ of $1 \mathrm{M}$ sodium methoxide for $20 \mathrm{~min}$. Methylation of any free fatty acids present in the original adipose sample was completed using $0.2 \mathrm{ml}$ of $5 \%$ methanolic $\mathrm{HCl}$, with methylation carried out at $80^{\circ} \mathrm{C}$ for $1 \mathrm{~h}$. Samples were then evaporated to dryness under nitrogen and dried for $5-10 \mathrm{~min}$ in an oven at $80^{\circ} \mathrm{C}$. FAMEs were dissolved in hexane to give a concentration of exactly $2 \%$ $\mathrm{w} / \mathrm{v}$, based on the weight of sample taken. Before sealing, approximately $20 \mathrm{mg}$ of anhydrous sodium sulphate was added to each vial to remove any residual traces of moisture from the extracts. The FAME solutions were stored at $-20^{\circ} \mathrm{C}$ until analysis by gas chromatography under the following conditions: SP2560 $(100 \mathrm{~m} \times 0.25 \mathrm{~mm}$ id, $20 \mathrm{pm}$ film thickness) flexible fused silica capillary column (Supelco, Bellefonte, PA, USA) in a Pye Unicam 610 FID gas chromatograph; split ratio $50: 1$; hydrogen $\left(0.8 \mathrm{ml} \mathrm{min}^{-1}\right)$ carrier gas; $1 \mu \mathrm{l}$ ( $2 \%$ FAME solution in hexane) injected sample; injector temperature of $240^{\circ} \mathrm{C}$; detector temperature of $260^{\circ} \mathrm{C}$. Resolution of cis-and trans-isomers was optimised using the following temperature programming: $150-180^{\circ} \mathrm{C}$ at $0.5^{\circ} \mathrm{C} \mathrm{min}{ }^{-1}, 180-210^{\circ} \mathrm{C}$ at $2^{\circ} \mathrm{C} \mathrm{min}^{-1}$. Peak areas were integrated using a Spectra Physics SP4290 integrator. FAMEs were confirmed by comparison of retention times of authentic standards run under the same conditions. These standards were sometimes 'spiked' into the FAME solution whenever there was doubt about the component identity in groups of closely eluting peaks. The content of linoleic acid and total TUFA was expressed as a percentage by weight $(\mathrm{g} / 100 \mathrm{~g})$ of total fat content.

\section{Data management}

To eliminate inter-interviewer bias, the main investigator carried out all interviews, coding and analysis. Nutrient intakes were calculated using the food/nutrient database (FOODBASE), which included analysis of 225 foods described previously. For composite recipe dishes, the nutrient content was calculated as the weighted consumption of each separate food product.

\section{Statistical analysis}

The mean difference in intake of each nutrient assessed by both methods was calculated as an estimate of the average bias of one method relative to the other. The limits of agreement (mean difference plus or minus two standard

Table 1 Demographic characteristics of participants who completed the fat intake questionnaire and diet history

\begin{tabular}{|c|c|c|c|}
\hline & Total $(n=105)$ & Males $(n=62)$ & Females $(n=43)$ \\
\hline & Mean (range) & Mean (range) & Mean (range) \\
\hline Age (years) & $38.5(23-63)$ & $40.8(28-63)$ & $35.1(23-56)$ \\
\hline Weight (kg) & $78.3(48-117)$ & $69.1(59-117)$ & $62.0(48-115)$ \\
\hline Height (m) & $1.72(1.54-1.94)$ & $1.77(1.63-1.94)$ & $1.65(1.54-1.77)$ \\
\hline $\mathrm{BMI}\left(\mathrm{kg} \mathrm{m}^{-2}\right)$ & $26.1(18.9-41.5)$ & $26.7(20.5-36.3)$ & $25.1(18.9-41.5)$ \\
\hline
\end{tabular}

BMI - body mass index. 
deviations of the difference $\left.\left( \pm 2 \mathrm{SD}_{\text {difference }}\right)\right)$ were also calculated for each nutrient to consider how well the methods agreed for an individual.

To exclude the possibility of a non-constant bias, i.e. a bias that depends on the level of intake, the difference between the two measures and the mean of the two measures were calculated for each individual ${ }^{13}$. The relationship between these parameters was studied by means of regression analysis, as advocated by Altman and Bland $^{13}$. The ability of the FIQ to classify individuals into the same quartile of intake as the DH was tested for each nutrient to evaluate agreement between both dietary assessment methods.

Pearson product-moment correlation coefficients were calculated to assess the association between the fatty acid composition of the diet, estimated by the FIQ and the DH, with the fatty acid composition of adipose tissue. Finally, the study group was divided into quartiles of long-chain fatty acid $\left(\mathrm{C}_{20}+\mathrm{C}_{22}\right)$ intake and a comparison of the total TUFA intake $(\mathrm{g} / 100 \mathrm{~g}$ fatty acids) and the total TUFA content of adipose tissue among these quartiles was performed. Statistical analyses were performed using SPSS software (Statistical Package for Social Sciences; SPSS Inc., Chicago, IL, USA).

\section{Results}

\section{Validation by comparison with the DH method}

The FIQ required on average $29 \mathrm{~min}$ to administer compared with $62 \mathrm{~min}$ for the DH. The mean differences in macronutrient intake assessed by the FIQ and the modified DH were not significantly different from zero (Table 2), indicating that the methods agreed excellently on average. The limits of agreement indicate that for a new subject we expect the two methods to differ in the assessment of total fat intake by approximately 8.4, SFA intake by 5 , MUFA by 4, PUFA by 3 , TUFA by 1.5 and linoleic acid by 3.2 (\% energy). Differences between individual pairs of intake estimates were not significantly related to the means for the majority of macronutrients, as demonstrated by regression analysis (Fig. 1). However, low intakes were underestimated and high intakes overestimated for polyunsaturated fat ( $\%$ energy) and vice versa for carbohydrate (\% energy) intake, resulting in a regression equation in which $\beta$ was 0.21 and -0.23 , respectively.

Mean differences in micronutrient intakes assessed by both methods were also comparable (Table 3), with the exception of vitamin D. A non-constant bias was also detected for vitamin $\mathrm{D}$, as low intakes were underestimated and high intakes overestimated $(\beta=0.45)$.

The ability of the FIQ to classify individuals into the same or adjacent quartile of intake as the $\mathrm{DH}$ ranged from $76 \%$ for linoleic acid (\% energy) to 91\% for energy (MJ), total fat $\left(\mathrm{g} \mathrm{day}^{-1}\right)$ and saturated fat $\left(\mathrm{g} \mathrm{day}^{-1}\right)$, shown in Table 4. The highest proportion of misclassification (i.e. classified from one extreme category to the other extreme category of intake) was 5\% for total TUFA (\% energy).

\section{Validation by comparison with adipose tissue biopsies}

Linoleic acid intake ( $\mathrm{g} / 100 \mathrm{~g}$ total fatty acids) assessed by the FIQ and the DH was significantly correlated with adipose tissue concentrations (g/100 g FAMEs) for the total group, with $r=0.58$ and $0.49(P<0.005)$, respectively (Table 5). In contrast, total TUFA intake assessed by the FIQ and the DH were poorly and not significantly

Table 2 Intakes of energy, macronutrients and dietary fibre, and ratio of energy intake to basal metabolic rate (EI/BMR), estimated using the fat intake questionnaire (FIQ) and diet history (DH) in 105 healthy adults

\begin{tabular}{|c|c|c|c|c|}
\hline Intake & $\frac{\mathrm{FIQ}}{\text { Mean (SD) }}$ & $\frac{\mathrm{DH}}{\operatorname{Mean}(\mathrm{SD})}$ & $\begin{array}{c}\text { Mean difference } \\
\text { (limits of agreement) } \dagger\end{array}$ & Correlation $\ddagger$ \\
\hline $\begin{array}{l}\text { Energy (MJ) } \\
\text { Fatty acids (\%E) }\end{array}$ & $10.6(3.0)$ & $10.6(2.7)$ & $-0.02(-3.3,3.3)$ & $0.78^{\star \star \star}$ \\
\hline Total & $33.9(6.2)$ & $34.2(6.1)$ & $0.28(-8.1,8.6)$ & $0.77^{\star \star \star}$ \\
\hline SFA & $12.7(3.8)$ & $12.6(3.7)$ & $-0.10(-5.1,4.9)$ & $0.77^{\star \star \star}$ \\
\hline MUFA & $10.4(2.2)$ & $10.8(2.5)$ & $0.39(-3.7,4.5)$ & $0.63^{\star \star \star}$ \\
\hline PUFA & $5.5(1.9)$ & $5.7(2.2)$ & $0.23(-2.8,3.3)$ & $0.73^{\star \star \star}$ \\
\hline TUFA & $1.9(0.9)$ & $1.8(0.9)$ & $-0.10(-1.6,1.4)$ & $0.67^{\star \star \star}$ \\
\hline Linoleic & $4.8(2.1)$ & $4.9(2.1)$ & $0.05(-3.1,3.2)$ & $0.71^{\star * \star}$ \\
\hline Alcohol (\%E) & $6.3(5.1)$ & $5.7(4.3)$ & $-0.04(-7.5,6.4)$ & $0.71^{\star \star \star}$ \\
\hline $\mathrm{CHO}(\% \mathrm{E})$ & $45.9(6.8)$ & $45.5(5.9)$ & $-0.43(-8.3,7.4)$ & $0.82^{\star \star \star}$ \\
\hline Protein (\%E) & $14.8(2.6)$ & $15.2(2.5)$ & $0.38(-3.9,4.7)$ & $0.64^{\star * \star}$ \\
\hline Fibre $(\mathrm{g}) \S$ & $26.9(9.2)$ & $26.9(9.7)$ & $0.07(-14.0,14.2)$ & $0.73^{\star \star \star}$ \\
\hline El/BMR & $1.50(0.4)$ & $1.51(0.4)$ & & \\
\hline
\end{tabular}

SD - standard deviation; \%E - percentage of energy; SFA - saturated fatty acids; MUFA - monounsaturated fatty acids; PUFA - polyunsaturated fatty acids; TUFA - trans unsaturated fatty acids; $\mathrm{CHO}$ - carbohydrate.

$\dagger$ Limits of agreement $=$ mean difference $(D H-F I Q) \pm 2 S D_{\text {difference }}$.

$\ddagger$ Pearson correlation.

$\S$ Southgate method.

${ }^{\star \star \star}$ Significant correlation between FIQ and DH: $P<0.0005$. 

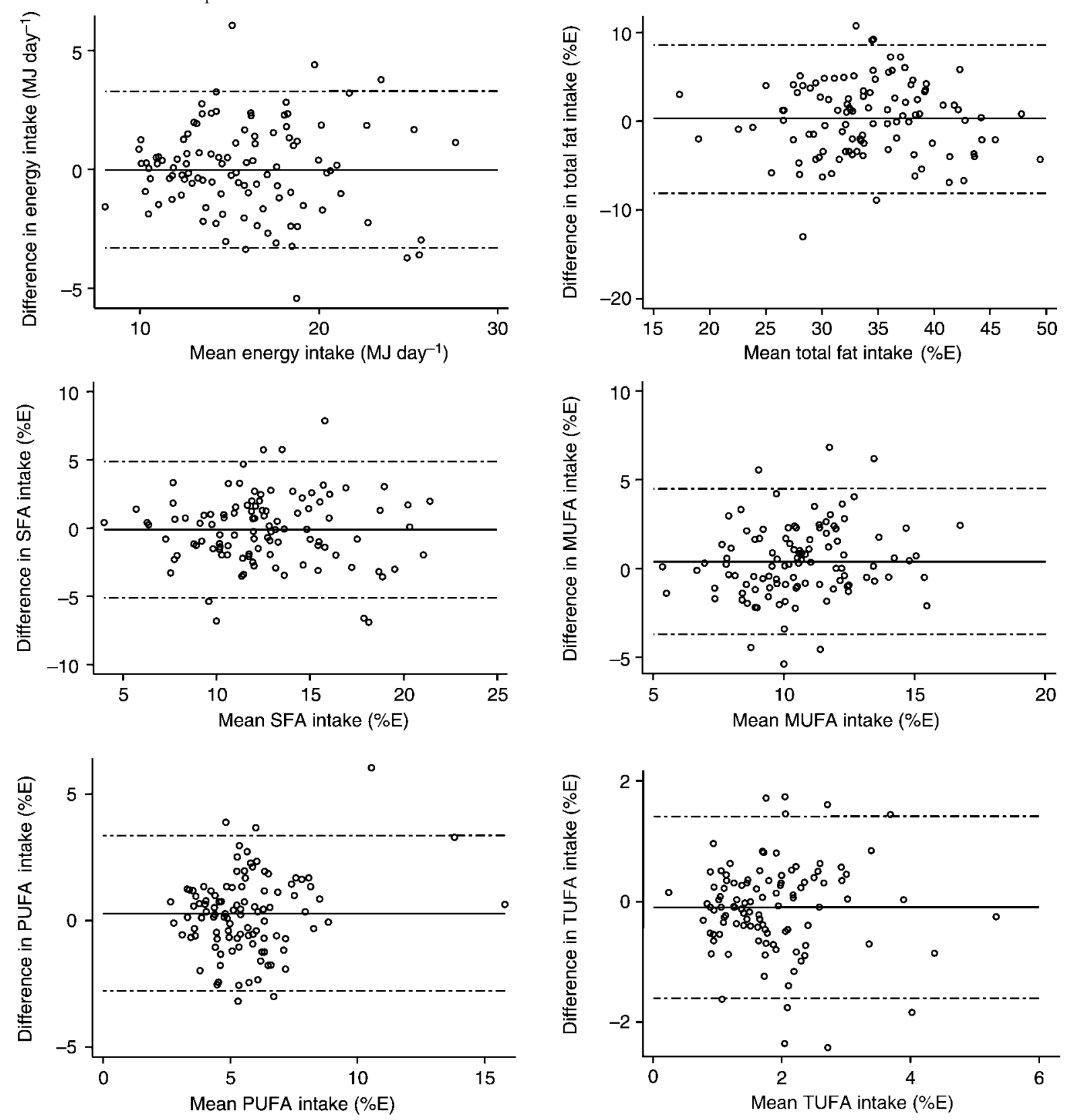

Fig. 1 Bland-Altman plots showing the relationship between the mean nutrient intake and the difference in nutrient intake assessed by the fat intake questionnaire and the diet history. Separate plots are shown for energy intake and for intake of each of the macro- and micronutrients assessed. The solid line indicates the mean difference between the two measures and the dashed lines indicate plus or minus two standard deviations of the difference $\left( \pm 2 S D_{\text {difference }}\right)$. \%E - percentage of energy; SFA - saturated fatty acids; MUFA monounsaturated fatty acids; PUFA - polyunsaturated fatty acids; TUFA - trans unsaturated fatty acids; ret equiv - retinol equivalents

correlated with adipose tissue concentrations $(r=0.17$ and 0.10 , respectively)

The study group $(n=84)$ was divided into quartiles based on their $\mathrm{C}_{20}+\mathrm{C}_{22}$ fatty acid intake (Table 6). Analysis indicated that total TUFA intake significantly differed between quartiles, with those in the top quartile of $\mathrm{C}_{20}+\mathrm{C}_{22}$ fatty acid intake having the greatest total TUFA intake. In addition, those in the top quartile of intake had the greatest total TUFA adipose tissue content. There was, however, no significant difference in adipose tissue TUFA amongst the quartiles.

\section{Discussion}

The results of this study indicate that the FIQ and the DH agreed excellently on average, with negligible mean differences in intake. However, the limits of agreement, which were calculated to assess the performance of the FIQ at the individual level, indicate that the FIQ does not assess intake of some nutrients as well as at the group level. Nevertheless, the FIQ's ability to classify individuals into the same or adjacent quartile of intake as the $\mathrm{DH}$ ranged between 76 and $91 \%$ for energy, total fat, SFA, 

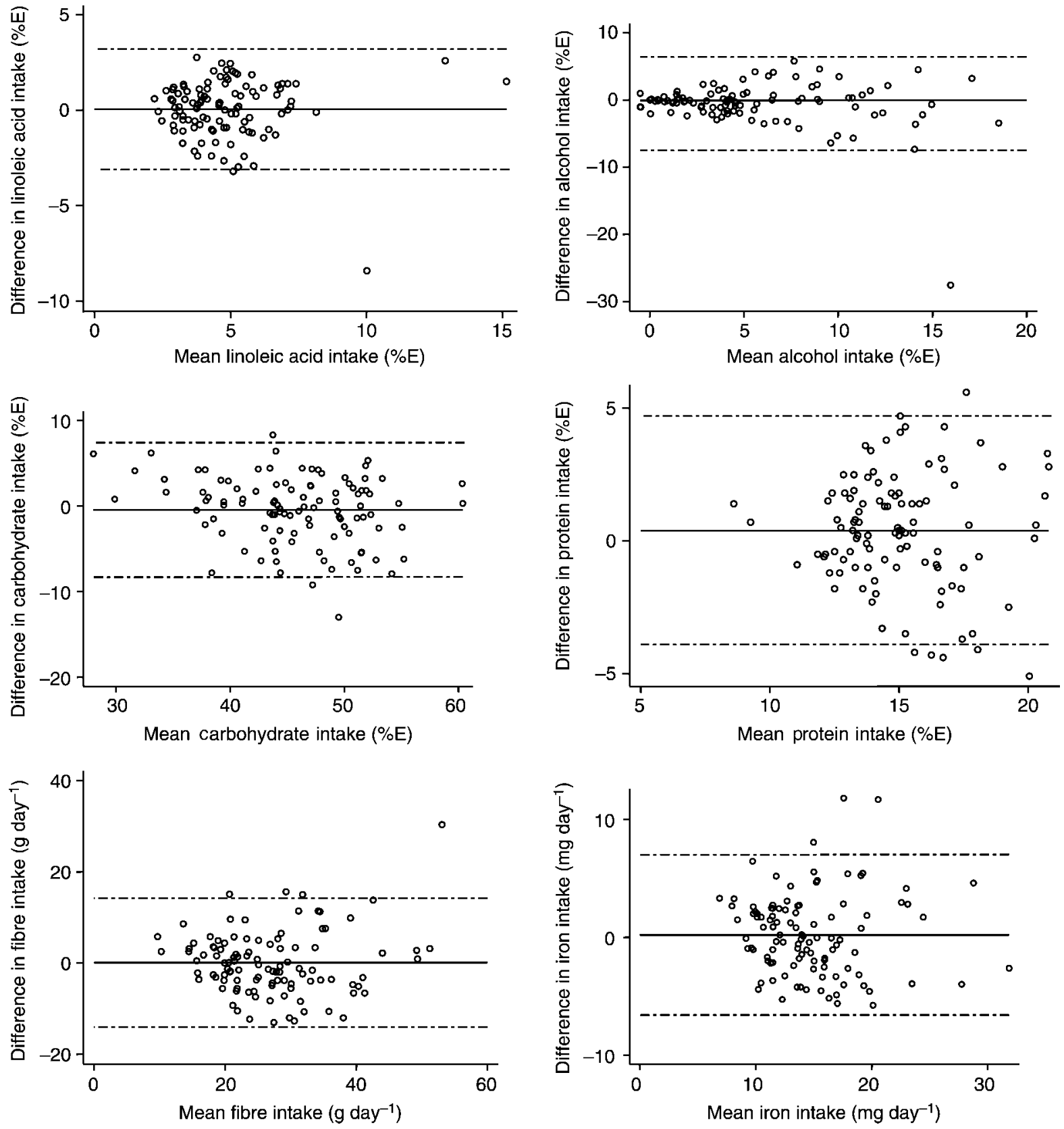

Fig. 1 Continued

MUFA, PUFA, linoleic acid and TUFA. Furthermore, the absolute validity of the FIQ was assessed as linoleic acid intake, which was significantly correlated with adipose tissue concentrations, a reliable indicator of long-term intake. In addition, the FIQ required far less time to complete compared with the $\mathrm{DH}$, and would therefore be preferable for use in large studies.

The relative validity of a new dietary assessment method is generally achieved by comparison with a reference method (a dietary assessment method considered to be more accurate), or absolute validity can be achieved by comparison with an independent marker of intake such as biomarker concentrations. The $\mathrm{DH}$ was chosen as the reference method in this study as it assesses habitual intake and had previously been validated against the doubly labelled water method for energy intake in Irish adolescents ${ }^{6}$.

The limits of agreement calculated in this study indicate that for a new subject we expect the two methods to differ in the assessment of total fat intake by approximately 8.4, SFA intake by 5 , MUFA by 4, PUFA by 3, TUFA by 1.5 and linoleic acid by 3.2 (\% energy). Validation studies are difficult to compare due to differences in the study population, the distribution of nutrient intakes and the methodology and statistical analyses used. However, most validation studies assess the validity at the individual level by assessing the questionnaire's ability to place individuals along a distribution of intake from low to high and by 

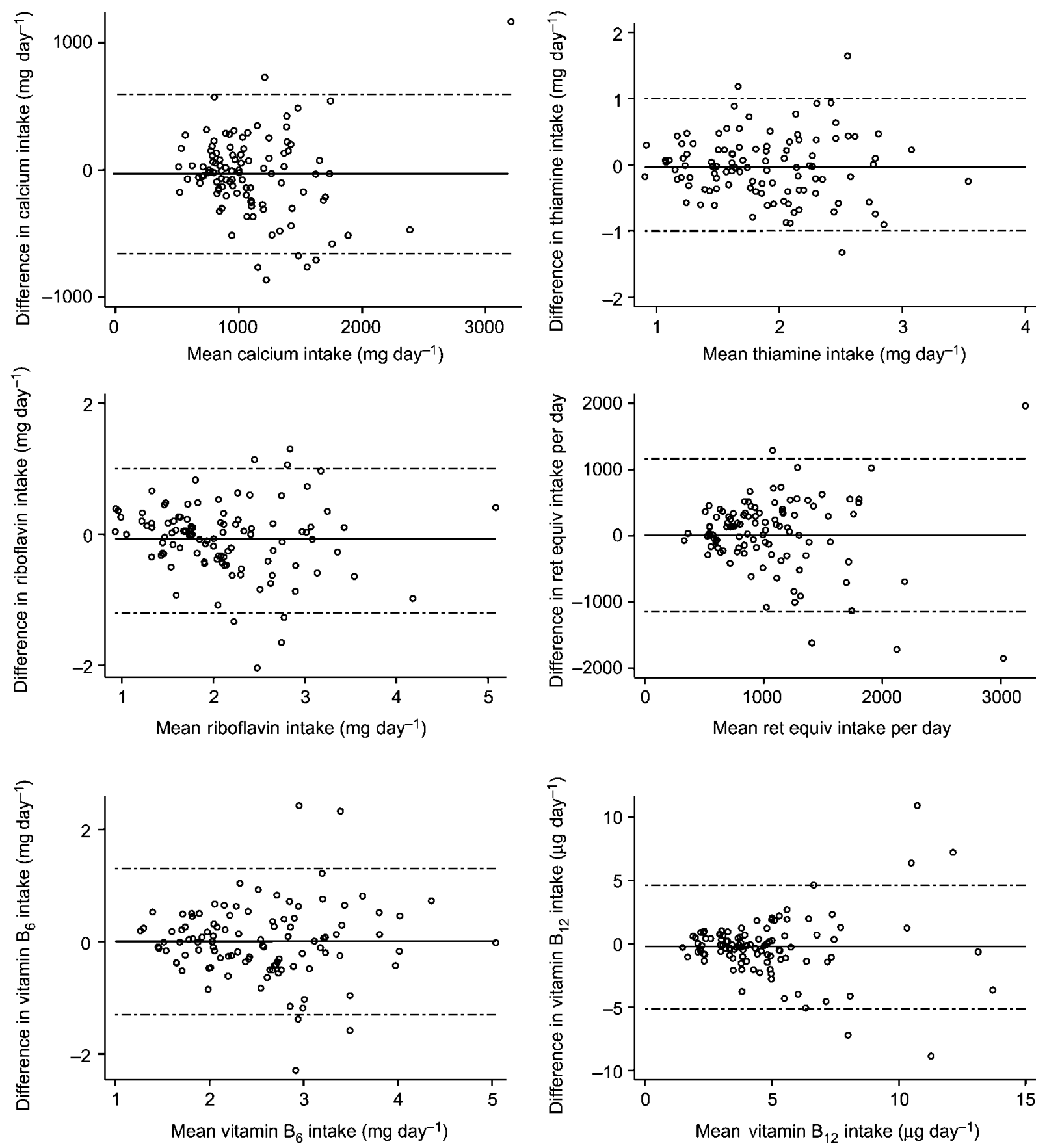

Fig. 1 Continued

using cross-categorisation by the two methods into tertiles, quartiles or quintiles ${ }^{14}$. The results of this study indicate that the FIQ's ability to assess the relative magnitude of an individual's intake of energy and their fatty acid profile is comparable to that of other studies which have used the diet history ${ }^{15}$ and dietary records ${ }^{16}$ as the reference method (Table 4).

This study showed that, for the majority of macro- and micronutrients, intake assessed by the FIQ was not affected by a non-constant bias. Exceptions were PUFA ( $\%$ energy) and vitamin D intakes, where low intakes were underestimated and high intakes were overestimated, and carbohydrate (\% energy) intake, where low intakes were overestimated and high intakes were underestimated.

Validity of the FIQ was also assessed by comparison with adipose tissue fatty acid concentrations. The half-life of adipose tissue in humans in energy balance is approximately 600 days and its composition should reflect the dietary fatty acid intake over the preceding 2.5 years ${ }^{7}$. Linoleic acid is generally accepted as a good indicator of intake since its appearance in adipose tissue is due primarily to dietary intake. The correlation coefficient 

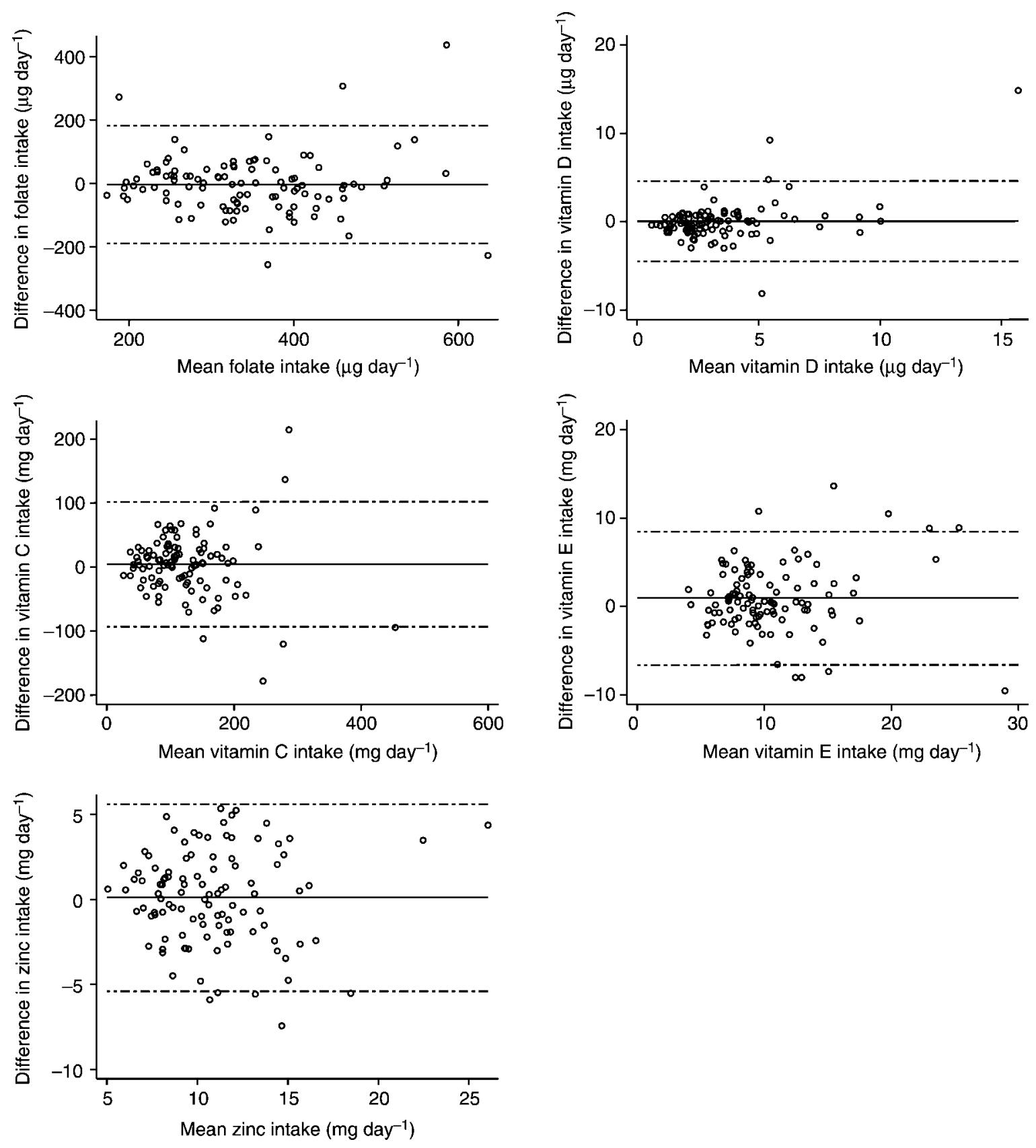

Fig. 1 Continued

( $r=0.58)$ of linoleic acid intake assessed by the FIQ and the adipose tissue content is comparable to previous studies, where correlations ranged from 0.28 to $0.70^{17-20}$. This provides additional support for the validity of the FIQ described in this study.

Five studies ${ }^{17,18,21-23}$ carried out in the USA and the UK have examined total TUFA intake in relation to adipose tissue concentrations and shown correlations of the order of $0.17-0.67$. The main source of TUFA in these studies was from hydrogenated vegetable oils, which produces transisomers of 18:1 and 18:2. However, in the Republic of Ireland, hydrogenated vegetable and marine oils are used in the food industry, providing - in addition to the trans 18:1 and trans 18:2 isomers - a variety of both positional and geometric isomers of longer-chain fatty acids $\left(\mathrm{C}_{20}\right.$ and $\mathrm{C}_{22}$ ). In the present study, gas chromatographic analysis of adipose tissue biopsies revealed an almost complete absence of TUFA other than geometric and positional isomers of 16:1, 18:1 and 18:2. Results showed that total TUFA in the diet was poorly correlated $(r=0.17)$ with total TUFA in adipose tissue. However, the study group $(n=84)$ was divided into quartiles based on their $\mathrm{C}_{20}+\mathrm{C}_{22}$ fatty acid intake. As expected, the total TUFA intake differed significantly between quartiles, with those subjects in 
Table 3 Intakes of micronutrients estimated using the fat intake questionnaire (FIQ) and diet history (DH) in 105 healthy adults

\begin{tabular}{|c|c|c|c|c|}
\hline \multirow[b]{2}{*}{ Intake } & \multirow{2}{*}{$\frac{\mathrm{FIQ}}{\text { Mean (SD) }}$} & \multirow{2}{*}{$\frac{\mathrm{DH}}{\text { Mean (SD) }}$} & \multirow{2}{*}{$\begin{array}{c}\text { Mean difference } \\
\text { (limits of agreement) } \dagger\end{array}$} & \multirow[b]{2}{*}{ Correlation } \\
\hline & & & & \\
\hline Iron (mg) & $14.6(4.9)$ & $14.8(4.7)$ & $0.2(-6.6,7.0)$ & $0.74^{\star \star *}$ \\
\hline Calcium (mg) & $1115.6(427)$ & $1080.2(437)$ & $-31.3(-657,595)$ & $0.71^{\star \star \star}$ \\
\hline Thiamine (mg) & $1.9(0.6)$ & $1.9(0.6)$ & $-0.03(-1.0,1.0)$ & $0.64^{\star \star \star}$ \\
\hline Riboflavin (mg) & $2.2(0.8)$ & $2.1(0.7)$ & $-0.07(-1.2,1.0)$ & $0.75^{\star \star \star}$ \\
\hline Retinol equivalents & 1058 (521) & 1048 (589) & $10.5(-1145,1166)$ & $0.47^{\star \star \star}$ \\
\hline Vitamin $B_{6}(\mathrm{mg})$ & $2.5(0.8)$ & $2.5(0.8)$ & $0.008(-1.3,1.3)$ & $0.67^{\star * \star}$ \\
\hline Vitamin $B_{12}(\mu \mathrm{g})$ & $4.9(2.8)$ & $4.6(2.8)$ & $-0.23(-5.0,4.6)$ & $0.60^{\star \star \star}$ \\
\hline Folate $(\mu \mathrm{g})$ & 343.6 (106.9) & $340.2(107.4)$ & $-3.01(-189,183)$ & $0.62^{\star \star *}$ \\
\hline Vitamin $D(\mu \mathrm{g})$ & $3.3(2.0)$ & $3.2(2.0)$ & $0.05(-4.5,4.6)^{\star \star}$ & $0.64^{\star \star \star}$ \\
\hline Vitamin C (mg) & 120.8 (71.2) & 125.7 (66.9) & $4.2(-93,102)$ & $0.75^{\star \star *}$ \\
\hline Vitamin E (mg) & $9.8(4.0)$ & $10.9(4.9)$ & $0.94(-6.6,8.5)$ & $0.68^{\star \star \star}$ \\
\hline Zinc (mg) & $10.8(3.6)$ & $10.9(3.6)$ & $0.11(-5.4,5.6)$ & $0.70^{\star \star *}$ \\
\hline
\end{tabular}

SD - standard deviation.

$\dagger$ Limits of agreement $=$ mean difference $(D H-F I Q) \pm 2 S D_{\text {difference. }}$.

$\ddagger$ Pearson correlation.

${ }^{\star *} \mathrm{FIQ}$ and DH estimates significantly different based on a paired $t$-test: $P<0.005$

${ }^{\star \star \star}$ Significant correlation between FIQ and DH: $P<0.0005$.

Table 4 Ability of the fat intake questionnaire to classify individuals into the same or adjacent quartile of nutrient intake as the diet history method $(n=105)$, expressed as $\%(n)$

\begin{tabular}{|c|c|c|c|}
\hline Nutrient & $\begin{array}{l}\text { Same } \\
\text { quartile }\end{array}$ & $\begin{array}{c}\text { Same or } \\
\text { adjacent } \\
\text { quartile }\end{array}$ & $\begin{array}{c}\text { Grossly } \\
\text { misclassified } \dagger\end{array}$ \\
\hline Energy (MJ) & $51(53)$ & $91(96)$ & $2(2)$ \\
\hline Total fat $\left(\mathrm{g}\right.$ alay $\left.^{-1}\right)$ & $53(56)$ & $91(96)$ & $2(2)$ \\
\hline Total fat (\%E) & $44(46)$ & $86(90)$ & $2(2)$ \\
\hline SFA $\left(\right.$ g day $\left.^{-1}\right)$ & $53(56)$ & $91(96)$ & $0(0)$ \\
\hline SFA $(\% \mathrm{E})$ & $47(49)$ & $90(95)$ & $1(1)$ \\
\hline MUFA $\left(\mathrm{g}^{\prime} \mathrm{day}^{-1}\right)$ & $60(63)$ & $85(89)$ & $0(0)$ \\
\hline MUFA (\%E) & $41(43)$ & $88(92)$ & $3(3)$ \\
\hline PUFA ( g day $\left.^{-1}\right)$ & $44(46)$ & $86(90)$ & $4(4)$ \\
\hline PUFA (\%E) & $45(47)$ & $83(87)$ & $4(4)$ \\
\hline Total TUFA ( g day $^{-1}$ ) & $48(50)$ & $89(93)$ & $2(2)$ \\
\hline Total TUFA (\%E) & $45(47)$ & $91(95)$ & $5(5)$ \\
\hline Linoleic acid $\left(\mathrm{g}\right.$ day $\left.^{-1}\right)$ & 37 (39) & $87(91)$ & $2(2)$ \\
\hline Linoleic acid (\%E) & $48(50)$ & $76(80)$ & $3(3)$ \\
\hline
\end{tabular}

\%E - percentage of energy; SFA - saturated fatty acids; MUFA - monounsaturated fatty acids; PUFA - polyunsaturated fatty acids; TUFA - trans unsaturated fatty acids.

†Classified from one extreme quartile to the other extreme quartile.

the top quartile of $\mathrm{C}_{20}+\mathrm{C}_{22}$ fatty acid intake having the greatest total TUFA intake and total TUFA adipose tissue content. However, there was no significant difference in total TUFA adipose tissue concentrations amongst quartiles. Clearly, longer-chain TUFA are not incorporated into adipose tissue to the same extent as trans-isomers of $\mathrm{C}_{18}$. This concept, which has been discussed previously ${ }^{24}$, can be explained by a decreased absorption of long-chain fatty acids with increasing chain length in humans ${ }^{25}$ and a reduced retention of 22:0, when fed as a component of hydrogenated fish oil, in the carcass fat of rats ${ }^{26}$.

It is possible that nutrient intakes assessed in the present study may be slightly biased because the study participants, who were volunteers, could be nutritionally more aware than persons who did not respond. However, it does not appear that total fat intake or the fatty acid profiles assessed in the present study differ substantially from population estimates in 2001 assessed by the North/South Ireland Food Consumption Survey ${ }^{27}$. For example, in the present study, total fat intake (\% energy) was 33.9 versus 34.8 and 35.6 for men and women, respectively, in the nationally representative sample. The FIQ, which was developed for use in Ireland, could be used by other investigators without additional changes, but would need to be re-validated for use in other ethnic or culturally different groups. As previously mentioned, if food manufacturers change the oils they use in margarine

Table 5 Comparison of fatty acid intake ( $\mathrm{g} / 100 \mathrm{~g}$ fat) assessed by the fat intake questionnaire (FIQ) and diet history (DH) with adipose tissue biopsies ( $\mathrm{g} / 100 \mathrm{~g}$ fatty acids) $(n=84)$

\begin{tabular}{|c|c|c|c|c|c|}
\hline \multirow[b]{2}{*}{ Fatty acid } & \multirow{2}{*}{$\frac{\text { Adipose tissue }}{\text { Mean (SD) }}$} & \multirow{2}{*}{$\frac{\text { FIQ }}{\text { Mean (SD) }}$} & \multirow{2}{*}{$\frac{\mathrm{DH}}{\text { Mean (SD) }}$} & \multicolumn{2}{|c|}{ Correlation $†$} \\
\hline & & & & $\begin{array}{c}\text { FIQ and adipose } \\
\text { tissue }\end{array}$ & $\begin{array}{c}\mathrm{DH} \text { and adipose } \\
\text { tissue }\end{array}$ \\
\hline Linoleic acid & $13.8(2.5)$ & $16.1(5.9)^{\star}$ & $16.6(6.4)^{\star}$ & $0.58^{\star \star}$ & $0.49^{* *}$ \\
\hline Total TUFA & $4.2(0.85)$ & $5.8(2.4)^{\star}$ & $5.4(2.5)^{*}$ & 0.17 & 0.10 \\
\hline
\end{tabular}

SD - standard deviation; TUFA - trans unsaturated fatty acids.

† Pearson correlation.

$\ddagger$ Gas chromatography method.

${ }^{*}$ Significantly different from adipose tissue concentration by paired $t$-test: $P<0.001$.

** Significant correlation: $P<0.005$ 
Table 6 Comparison of total trans unsaturated fatty acids (TUFA) intake $(\mathrm{g} / 100 \mathrm{~g}$ fat) and total TUFA content of adipose tissue ( $\mathrm{g} / 100 \mathrm{~g}$ fatty acids) based on quartiles of trans $\mathrm{C}_{20}$ and $\mathrm{C}_{22}$ fatty acid intake

\begin{tabular}{|c|c|c|}
\hline \multirow{2}{*}{$\begin{array}{l}\text { Quartile } \\
\text { of } C_{20}+C_{22} \text { intake }\end{array}$} & \multirow{2}{*}{$\frac{\text { Total TUFA intake }}{\text { Mean (SD) }}$} & \multirow{2}{*}{$\begin{array}{l}\text { Adipose tissue } \\
\text { TUFA content } \\
\text { Mean (SD) }\end{array}$} \\
\hline & & \\
\hline 1 & $3.76(1.04)$ & $4.01(1.06)$ \\
\hline 2 & $4.99(1.46)^{\star, a}$ & $4.10(0.93)$ \\
\hline 3 & $6.23(1.72)^{*, a, b}$ & $4.35(0.73)$ \\
\hline 4 & $8.18(2.38)^{\star, a, b, c}$ & $4.42(0.58)$ \\
\hline
\end{tabular}

* One-way analysis of variance with Bonferroni adjustment.

a Significantly different from quartile 1: $P<0.05$.

${ }^{b}$ Significantly different from quartile $2: P<0.05$.

${ }^{\mathrm{c}}$ Significantly different from quartile $3: P<0.05$.

production then the fatty acid composition of all products manufactured from this margarine will also vary. Investigators must acknowledge this and if detailed fatty acid intake data are required, then some direct analysis of foods may be necessary.

Finally, the excellent agreement between mean nutrient intakes assessed by the FIQ and the DH, the absence of a non-constant bias for most nutrients and the ability of the FIQ to classify individuals adequately demonstrate an acceptable relative validity. In addition, the independent validation of the FIQ for linoleic acid intake by comparison with adipose tissue concentrations provides additional evidence that the FIQ could be used in studies that require a shorter dietary assessment method.

\section{Acknowledgements}

Support from the Strategic Research and Development Fund, Dublin Institute of Technology, the Non-Commissioned Food Research Programme administered by the Department of Agriculture, Food and Rural Development and the National Dairy Council, Ireland is gratefully acknowledged.

\section{References}

1 National Research Council, Committee on Diet and Health, Food and Nutrition Board, Commission on Life Sciences. Diet and Health. Implications for Reducing Chronic Disease Risk. Washington, DC: National Academy Press, 1989.

2 Ulbricht TLV, Southgate DAT. Coronary heart disease: seven dietary factors. Lancet 1991; 338: 985-92.

3 Hu FB, Stampfer MJ, Manson JE, Ascherio A, Colditz GA, Speizer FE, et al. Dietary saturated fats and their food sources in relation to the risk of coronary heart disease in women. American Journal of Clinical Nutrition 1999; 70(6): 1001-8.

4 Kris-Etherton PM, Yu S. Individual fatty acid effects on plasma lipids and lipoproteins: human studies. American Journal of Clinical Nutrition 1997; 65(Suppl.) $1628 \mathrm{~S}-44 \mathrm{~S}$.

5 Lee P, Cunningham K. Irish National Nutrition Survey. Dublin: Irish Nutrition and Dietetic Institute, 1990.

6 Livingstone MB, Prentice AM, Coward WA, Strain JJ, Black
$\mathrm{AE}$, Stewart $\mathrm{CM}$, et al. Validation of estimates of energy intake by weighed dietary record and diet history in children and adolescents. American Journal of Clinical Nutrition 1992; 56: 29-35.

7 Hirsch J, Farquhar J, Ahrens EH, Peterson ML, Stoffel W. Studies of adipose tissue in man - a micro technique for sampling and analysis. American Journal of Clinical Nutrition 1960; 8: 499-511.

8 Flynn MAT. Nutritional issues in cardiac dietetics. PhD thesis. University of Dublin, Trinity College Dublin, Ireland, 1993.

9 Crawley H. Food Portion Sizes. London: HMSO, 1988.

10 O'Neill J. Trans fatty acids - occurrence and measurement in foodstuffs and uptake in a selected population group. $\mathrm{PhD}$ thesis, National University of Ireland, 1998.

11 Cronin DA, O'Neill J. Trans fatty acid status of Irish food products. Proceedings of the Nutrition Society 1995; 54: 179A.

12 Buzzard IM, Price KS, Warren RA. Considerations for selecting nutrient-calculation software: evaluation of the nutrient database. American Journal of Clinical Nutrition 1991; 54: 7-9.

13 Altman DG, Bland JM. Measurement in medicine: the analysis of method comparison studies. The Statistician 1983; 32: 307-17.

14 Block G, Hartman AM. Issues in reproducibility and validity of dietary studies. American Journal of Clinical Nutrition 1989; 50: 1133-8.

15 Grootenhuis PA, Westenbrink S, Sie CM, de Neeling JN, Kok FJ, Bouter LM. A semi-quantitative food frequency questionnaire for use in epidemiologic research among the elderly: validation by comparison with dietary history. Journal of Clinical Epidemiology 1995; 48(7): 859-68.

16 Pietinen P, Hartman AM, Haapa E, Rasanen L, Haapakoski J, Palmgren $\mathrm{J}$, et al. Reproducibility and validity of dietary assessment instruments. I. A self-administered food use questionnaire with a portion-size picture booklet. American Journal of Epidemiology 1988; 128: 655-66.

17 Hunter DJ, Rimm ER, Sacks FM, Stampfer MJ, Colditz GA, Litin LB, et al. Comparison of measures of fatty acid intake by subcutaneous fat aspirate, food frequency questionnaire, and diet records in a free-living population of US men. American Journal of Epidemiology 1992; 135: 418-27.

18 London SJ, Sacks FM, Caesar J, Stampfer MJ, Siguel E, Willett W. Fatty acid composition of subcutaneous adipose tissue and diet in postmenopausal US women. American Journal of Clinical Nutrition 1991; 54: 340-5.

19 Van Staveren WA, Deurenberg P, Katan MB, Burema J, De Groot LCPGM, Hoffmans MDAF. Validity of the fatty acid composition of subcutaneous fat tissue micro-biopsies as an estimate of the long-term average fatty acid composition of the diet of separate individuals. American Journal of Epidemiology 1986; 123: 455-63.

20 Feunekes GIJ, Van Staveren WA, De Vries JHM, Burema J, Hautvast GAJ. Relative and biomarker-based validity of a food-frequency questionnaire estimating intake of fats and cholesterol. American Journal of Clinical Nutrition 1993; 58: $489-96$.

21 Garland M, Sacks FM, Colditz GA, Rimm EB, Sampson LA, Willett WC, et al. The relation between dietary intake and adipose tissue composition of selected fatty acids in US women. American Journal of Clinical Nutrition 1998; 67: 25-30.

22 Willett WC, Sampson L, Stampfer MJ. Reproducibility and validity of a semi-quantitative food frequency questionnaire. American Journal of Epidemiology 1985; 122: 51-65.

23 Lemaitre RN, King IB, Patterson RE, Psaty BM, Kestin M, Heckbert SR. Assessment of trans-fatty acid intake with a food frequency questionnaire and validation with adipose tissue levels of trans fatty acids. American Journal of Epidemiology 1998; 148: 1085-93. 
24 Cantwell MM. Assessment of individual fatty acid intake. Proceedings of the Nutrition Society 2000; 59: 187-91.

25 Peters JC, Holcombe BN, Hiller LK, Webb DR. Caprenin 3. Absorption and caloric value in adult humans. Journal of the American College of Toxicology 1991; 10(3): 357-67.

26 Webb DR, Peters JC, Jandacek RJ, Fortier NE. Caprenin 2. Short-term safety and metabolism in rats and hamsters.
Journal of the American College of Toxicology 1991; 10(3): 341-56.

27 Harrington KE, McGowan MJ, Kiely M, Robson PJ, Livingstone MB, Morrissey PA, Gibney MJ. Macronutrient intakes and food sources in Irish adults: findings of the North/South Ireland Food Consumption Survey. Public Health Nutrition 2001; 4(5A): 1051-60. 